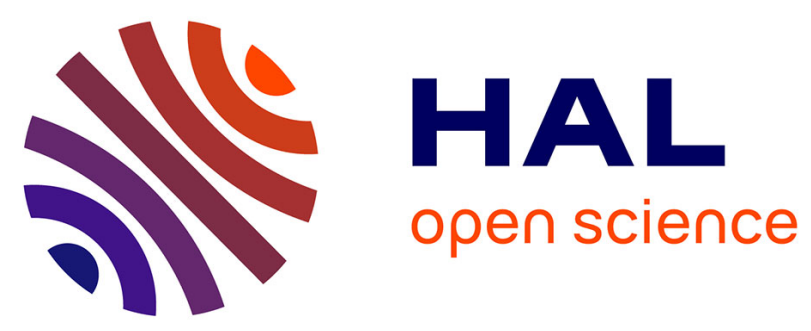

\title{
Assessment of the unsaturated water transport properties of an old concrete: Determination of the pore-interaction factor
}

Stéphane Poyet, Sébastien Charles, Nicolas Honoré, Valérie L'Hostis

\section{To cite this version:}

Stéphane Poyet, Sébastien Charles, Nicolas Honoré, Valérie L'Hostis. Assessment of the unsaturated water transport properties of an old concrete: Determination of the pore-interaction factor. Cement and Concrete Research, 2011, 41, pp.1015 - 1023. 10.1016/j.cemconres.2011.06.002 . cea-03293541

\section{HAL Id: cea-03293541 \\ https://hal-cea.archives-ouvertes.fr/cea-03293541}

Submitted on 21 Jul 2021

HAL is a multi-disciplinary open access archive for the deposit and dissemination of scientific research documents, whether they are published or not. The documents may come from teaching and research institutions in France or abroad, or from public or private research centers.
L'archive ouverte pluridisciplinaire HAL, est destinée au dépôt et à la diffusion de documents scientifiques de niveau recherche, publiés ou non, émanant des établissements d'enseignement et de recherche français ou étrangers, des laboratoires publics ou privés. 


\title{
Assessment of the unsaturated water transport properties of an old concrete: Determination of the pore-interaction factor
}

\author{
Stéphane Poyet* , Sébastien Charles, Nicolas Honoré, Valérie L'hostis \\ CEA, DEN, DPC, SCCME, Laboratoire d'Étude du Comportement des Bétons et des Argiles, F-91191 Gif sur Yvette Cedex, France
}

\section{A R T I C L E I N F O}

\section{Article history:}

Received 15 July 2010

Accepted 6 June 2011

\section{Keywords:}

Concrete

Water transport

Unsaturated transport properties

Pore-interaction factor

\begin{abstract}
A B S T R A C T
In this study all the data needed to describe water transport (drying) within an existing concrete structure were characterized using a simple drying experiment. The properties (desorption isotherm, porosity and the unsaturated water transport properties namely, diffusivity and permeability) were evaluated by postprocessing the weight loss data. Once obtained, the permeability evolution was used to check the validity of the Mualem-van Genuchten equations. It appeared that the default pore-interaction factor value proposed by Mualem $(p=+0.5)$ is just a rough estimate: the values obtained in this study were all negative. Comparing these values to the literature, the pore-interaction factor seems to be correlated to the van Genuchten's exponent $m$.
\end{abstract}

(c) 2011 Elsevier Ltd. All rights reserved.

\section{Introduction}

Water plays a very important role in the durability of concrete structures. For example, the well-known results of Tuutti [36] show that for a carbonated concrete the corrosion current is maximal for a Relative Humidity ( $\mathrm{RH}$ ) of about $95 \%$ and then drastically decreases with $\mathrm{RH}$. In fact water significantly impacts reinforced concrete durability through many different ways:

- the concrete mechanical properties and delayed deformations (drying shrinkage, creep) are greatly influenced by water content which may lead to cracking;

- the transfer properties are greatly influenced by the moisture content;

- for pathologies involving in solution chemical reactions (such as carbonation or reinforcement corrosion), water is the reaction medium; the less free water, the less the probability of occurrence of the involved chemical reactions.

The durability assessment of concrete structures in relation to their environment thus requires an accurate description of the water transfer all along their service life. This is commonly achieved in a simplified way using a single equation which accounts for liquid water transport driven by pressure gradients only. The other motions (diffusion and gaseous permeation) are neglected. This was proven to be true for low-permeability cementitious materials [25,34,35]. The

\footnotetext{
* Corresponding author.

E-mail address: stephane.poyet@cea.fr (S. Poyet).
}

water mass flow can be described using the well known Darcy's law extended to unsaturated flow [29]:

$j_{w}=-\rho K \frac{k_{r}}{\eta} \underline{\operatorname{grad}}(P)$,

where $P$ is the liquid water pressure $(\mathrm{Pa}) ; \eta$ and $\rho$ are the water viscosity (Pa s) and density $\left(\mathrm{kg} / \mathrm{m}^{3}\right) ; K$ is the intrinsic permeability to water $\left(\mathrm{m}^{2}\right)$, it characterizes the resistance of the saturated concrete to water flow under a pressure gradient; and $k_{r}$ is the relative permeability to water (without unit), it ranges between 0 (dry state) and 1 (saturated state) and describes the influence of water content on the porous network percolation.

The equation of continuity (water mass conservation) writes:

$\frac{\partial}{\partial t}(\rho \phi S)=-\operatorname{div}\left(-j_{-w}\right)$,

where $S$ is the saturation index (fraction of the pore volume occupied by water, without unit), it ranges between 0 (dry state) and 1 (saturated state) and $\phi$ is the concrete porosity (without unit).

In isothermal conditions, assuming that water is incompressible and that a derivable relation between concrete saturation $S$ and water pressure $P$ exists (this relation is known as the capillary curve), one can obtain two simple equations depending on the choice of the unknown variable (water pressure $P$ or saturation $S$ ) $[25,10]$ :

$\phi\left(\frac{\partial S}{\partial P}\right) \frac{\partial P}{\partial t}=\operatorname{div}\left[K \frac{k_{r}}{\eta} \operatorname{grad}(P)\right]$ 
$\frac{\partial S}{\partial t}=\operatorname{div}[D(S) \operatorname{grad}(S)]$

where $D$ is the water and diffusivity $\left(\mathrm{m}^{2} / \mathrm{s}\right)$. In Eq. (3) the term $\left(\frac{\partial S}{\partial P}\right)$ can be rewritten as $\left(\frac{\partial S}{\partial P}\right)=\left(\frac{\partial S}{\partial h}\right)\left(\frac{\partial h}{\partial P}\right)$, where $\left(\frac{\partial h}{\partial P}\right)=-\frac{P M}{\rho R T} \exp$ $\left(-\frac{P M}{\rho R T}\right)$ is the derivative of the reciprocal Laplace law and $\left(\frac{\partial S}{\partial h}\right)$ is the derivative of the desorption isotherm. The description of water transport within concrete using the diffusion Eq. (4) thus requires the knowledge of only one physical property: the moisture diffusivity $D$, whereas using Eq. (3) requires four of them: the porosity to water $\phi$; the sorption isotherm $S=S(h)$; the intrinsic permeability to water $K$ and the relative permeability to water $k_{r}$.

The porosity to water can be easily and quickly characterized by complete drying (for example at $105^{\circ} \mathrm{C}$ ), yet the other properties are more difficult to acquire. The sorption isotherm describes the concrete water content at equilibrium with any arbitrary external RH. It can be obtained by submitting concrete samples to different RHs (in isothermal conditions) and waiting for equilibrium [5]. This is a very long process which also requires frequent weighing (to check equilibrium). The water transport properties (intrinsic permeability and diffusivity) can be directly measured: for instance using water permeametry and cup-method tests for permeability and diffusivity respectively [6]. Such direct measurements are however known to yield too-high values (by a few orders of magnitude) which lead to drying kinetics overestimation. They are then usually estimated through an inverse analysis using Eqs. (3-4) and experimental sample mass loss $[5,25,10]$. In so doing, the relative permeability to water $k_{r}$ is always estimated using the model derived by Mualem [28] and the consistent set of equations proposed by van Genuchten [37,38].

The model proposed by Mualem [28] creates a link between the retention curve and the relative permeability to water $k_{r}$. It is based on the description of the interconnected-pores distribution of porous materials: when the retention curve is known, Mualem's model allows estimating $k_{r}$ in a simple integral form. After that, van Genuchten [37] proposed a simple equation to describe the retention curve which once introduced into Mualem's model yields another simple analytical equation for the relative permeability $k_{r}$ :

$\left\{\begin{array}{l}S=\left[1+\left(P / P_{0}\right)^{\frac{1}{1-\mathrm{m}}}\right]^{-m} \\ k_{r}=S^{p}\left[1-\left(1-S^{\frac{1}{m}}\right)^{m}\right]^{2}\end{array}\right.$

where $P$ is the water pressure; $m$ and $P_{0}$ are two positive parameters and $\left(P_{0}\right.$ is equivalent to a pressure). The pore-interaction factor $p$ is a constant which describes the effect of pore discontinuity and tortuosity; it is taken equal to +0.5 by default. Note that the $m$ parameter is the same in the two equations. Mualem's model together with the equations of van Genuchten were initially developed for soils but they were applied for the first time to cementitious materials by Savage and Janssen [30] who concluded that they were successful in reproducing the experimental mass loss curves of hardened cement pastes. Yet the authors do not give any information about the

Table 1

Saturated salt solutions used and resulting RHs [9,32,41,16,8].

\begin{tabular}{lll}
\hline Salt used formula & & $\mathrm{RH}$ \\
\hline Potassium nitrate & $\mathrm{KNO}_{3}$ & $93 \%$ \\
Potassium bromide & $\mathrm{KBr}$ & $81 \%$ \\
Sodium bromide & $\mathrm{NaBr}$ & $59 \%$ \\
Magnesium chloride & $\mathrm{MgCl}{ }_{2} 6 \mathrm{H}_{2} 0$ & $33 \%$ \\
Lithium chloride & $\mathrm{LiCl}$ & $11 \%$ \\
\hline
\end{tabular}

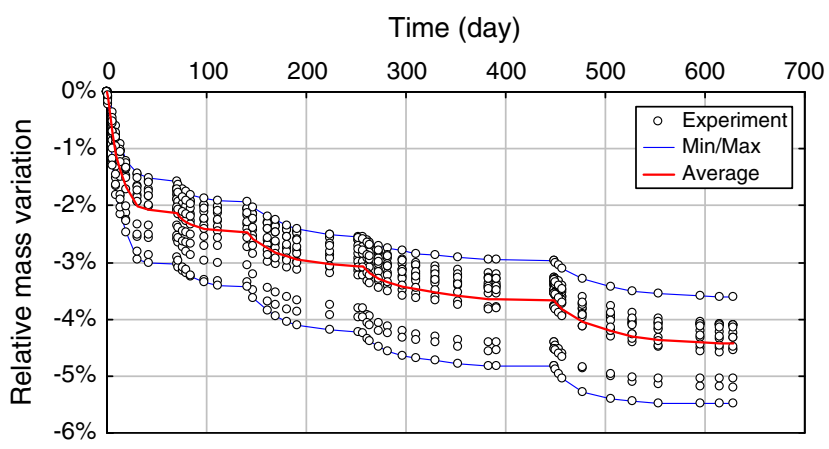

Fig. 1. Sample relative mass variation vs. time (oven-drying at $105{ }^{\circ} \mathrm{C}$ is not reported). Each open circle corresponds to an experimental value (sample); the solid lines represent the average, minimal and maximal values respectively.

predictive ability of the relative permeability to water of the Mualemvan Genuchten model. Recently Leech et al. [24] studied the sorptivity of three different concretes $(\mathrm{w} / \mathrm{c}=0.40 ; 0.55$ and 0.62 ) using Nuclear Magnetic Resonance (NMR): they showed that Mualem-van Genuchten model adequately predicts the Boltzmann profile for each sample as far as the pore-interaction factor $p$ is fitted together with the intrinsic permeability. The resulting values varied between -0.2 and -1.2 which led the authors to propose $p=-0.5$ as a default value.

In fact in soil science, the pore-interaction factor $p$ is known to depend on the considered material: for instance Mualem [28] analyzed the hydraulic properties of 45 soils. He noted that $p$ could be either positive or negative and proposed +0.5 as a universal default value. Later Wösten and van Genuchten [40], working on 20 different soils, obtained values ranging from -16.0 to +2.2 . They also showed that in some cases (medium and fine-textured soils) using $p=+0.5$ did result in unacceptable fits. Schuh and Cline [31] in a similar approach showed great variability (from -8.7 to +14.8 ): the geometric mean was however found to be close to Mualem's proposition $(+0.6)$. Unfortunately no trend relationship between the pore-interaction factor $p$ and the van Genuchten parameters (namely $m, n$ and $P_{0}$ in Eq. (9) could be found. Using a 200-soil data set Kosugi [22] obtained the same kind of results (from -14.0 to +14.0 with $71 \%$ of the values being negative) and eventually proposed -0.5 or -0.8 as a default value (depending on the optimization procedure).

In the field of cement-based materials $p=+0.5$ has been used so far. Beyond the results obtained by Leech et al. [24] $(p=-0.5)$, Monlouis-Bonnaire et al. [27] and Wardeh and Perrin [39] proposed to use $p=+5.5$ on the basis of relative gas permeability measurements using an ordinary concrete $(\mathrm{w} / \mathrm{c}=0.48)$ preconditioned at $50{ }^{\circ} \mathrm{C}$. It appears clearly that results are lacking and further studies are needed to clarify the value of the pore-interaction factor $p$ for cementitious materials. In this study, the unsaturated water transport properties of a concrete taken from an existing structure were characterized: the results were then used to check the predictive capacity of the Mualem-van Genuchten model and to estimate the concrete poreinteraction factor $p$.

\section{Experimental campaign}

The considered structure is a wind-tunnel ${ }^{1}$ built in the early 30 s but the zone of interest was added during the 50s. The concrete composition is not known, yet it is an ordinary concrete based on CEM II cement (clinker + carbonate filler) which is believed to be

\footnotetext{
${ }^{1}$ Wind-tunnel S1Ch, ONERA (aerospace research, http://www.onera.fr), Meudon, France.
} 
representative of everyday concrete of the 50s. Since the wind-tunnel is a historical monument, only a limited number of samples could be extracted by coring ( $40 \mathrm{~mm}$ diameter and $\sim 60 \mathrm{~mm}$ height). Among all of them, only 15 could be used for this study. Both ends were sawn and removed (about $5-10 \mathrm{~mm}$ ). This was not done to obtain noncarbonated samples but to remove potentially cracked sample parts. After a fifty-year exposure to the atmosphere, the samples were believed to present a several centimeter deep carbonated zone. The samples were then kept underwater for one month to have them saturated (the initial saturation was verified using vacuum resaturation which showed no water uptake).

Due to the small number of samples and the variability expected on a field concrete from a real structure, a unique sample set was considered (including all the samples). Variability could be observed on the samples through the difference in the presence and number of entrapped air bubbles. Moreover two samples (which were discarded) presented massive honeycombing (voids due to the absence of mortar between aggregates).The initially saturated samples were put in a closed chamber in which the RH was regulated using saturated salt solutions $[9,32,41,16,8]$. Periodically the chamber was opened and the samples were weighed. In order to monitor the samples drying kinetics the indicator $\varepsilon$ was calculated as follows:

$\varepsilon=\frac{\left|\left(\frac{m}{m}\right)_{\infty}-\left(\frac{m}{m}\right)_{t}\right|}{\left(\frac{m}{m}\right)_{\infty}}$

where $\left(\frac{m}{m}\right)_{t}$ is the relative mass variation at the time $t$ and $\left(\frac{m}{m}\right)_{\infty}$ is the relative mass variation at equilibrium. The latter was estimated by fitting the following simple exponential formula to the experimental mass variations:

$\left(\frac{\mathrm{m}}{\mathrm{m}}\right)_{t}=\left(\frac{\mathrm{m}}{\mathrm{m}}\right)_{\infty}\left[1-\exp \left(-\frac{t}{\tau}\right)\right]$

Note that this simple formula corresponds to the analytical solution of the diffusion equation within a solid cylinder [11] using only one term (as suggested by [33]). When the error estimator $\varepsilon$ was strictly less than $5 \%$ for all the samples, a lower $\mathrm{RH}$ was imposed using another saturated salt solution. This criterion appeared afterwards not to be strict enough: the samples were more or less out of equilibrium at the end of each RH-step. This point is addressed in Section 3.2

The different salts used and the resulting RHs are given in Table 1. A special attention was paid to $\mathrm{RH}$ regulation: a thermo-hygrometer

Table 2

Density, porosity and water content at saturation.

\begin{tabular}{lccc}
\hline Sample & Saturated density $d_{s}$ & Porosity $\phi$ & Water content at saturation $w_{\text {sat }}$ \\
\hline 1 & 2.330 & $17.1 \%$ & $7.90 \%$ \\
2 & 2.345 & $13.9 \%$ & $6.32 \%$ \\
3 & 2.370 & $14.0 \%$ & $6.27 \%$ \\
4 & 2.394 & $12.6 \%$ & $5.57 \%$ \\
5 & 2.349 & $15.7 \%$ & $7.16 \%$ \\
6 & 2.354 & $15.4 \%$ & $7.88 \%$ \\
7 & 2.294 & $16.8 \%$ & $7.14 \%$ \\
8 & 2.346 & $15.6 \%$ & $6.43 \%$ \\
9 & 2.308 & $16.2 \%$ & $6.14 \%$ \\
10 & 2.351 & $14.2 \%$ & $5.99 \%$ \\
11 & 2.366 & $13.7 \%$ & $6.96 \%$ \\
12 & 2.381 & $13.5 \%$ & $6.22 \%$ \\
13 & 2.324 & $15.1 \%$ & $6.55 \%$ \\
14 & 2.363 & $13.8 \%$ & $6.48 \%$ \\
15 & 2.356 & $14.5 \%$ & $6.68 \%$ \\
Average & 2.354 & $14.7 \%$ & $6.58 \%$ \\
Std dev. & 0.025 & $1.2 \%$ & $0.67 \%$ \\
COV & $1 \%$ & $8 \%$ & $10 \%$ \\
\hline
\end{tabular}

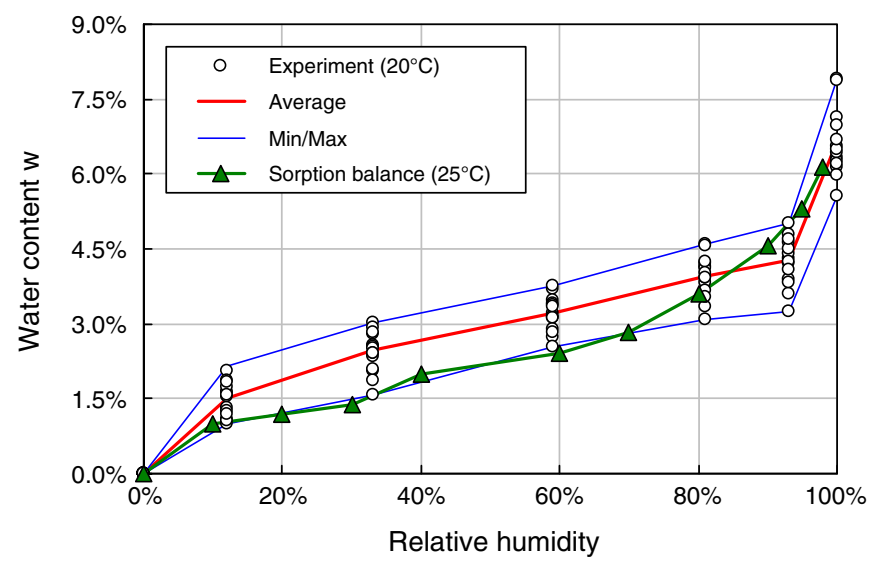

Fig. 2. Presentation of the concrete desorption isotherm: the open circles represent the experimental results obtained using the saturated salt solution method at $20^{\circ} \mathrm{C}$ (concrete cylinders) whereas the triangles represent the results obtained using the commercial sorption balance at $25{ }^{\circ} \mathrm{C}$ (powdered concrete).

was inserted in the chamber to check RH and a pump was added to ensure air circulation and $\mathrm{RH}$ homogeneity within the chamber.

The experiments were conducted in an air-conditioned room at $20 \pm 1.5{ }^{\circ} \mathrm{C}$ for more than 600 days. No preventive action was undertaken to prevent carbonation since the samples were believed to be at least partially carbonated (after a 50-year exposure to the atmosphere) and because of their low specific surface area (carbonation would then affect only a small part of the total volume).

The mass loss at equilibrium (with the $\mathrm{RH}$ controlled by the saturated solution) was expected to yield the desorption isotherm. The total porosity was estimated by complete drying at $105^{\circ} \mathrm{C}$ as an ultimate step in the desorption process. The water transport properties were then evaluated by processing the experimental mass loss as already proposed by many authors $[12,33,14,1]$.

\section{Results}

\subsection{Relative mass variation}

Fig. 1 presents the relative mass variation of the samples over the whole experiment duration (nearly two years). The open circles represent the experimental data for each sample, whereas the solid lines stand for the average, minimal and maximal values. The ovendrying at $105{ }^{\circ} \mathrm{C}$ is not reported. The porosity values obtained are reported in Table 2 . They appeared to vary in the range $12.6 \%$ to $17.1 \%$ with an average value equal to $14.8 \%$.

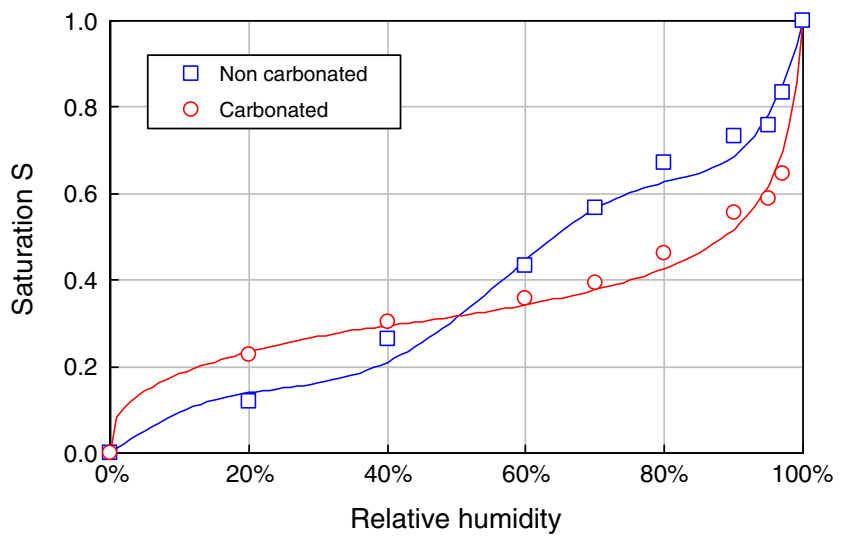

Fig. 3. Desorption isotherm of an ordinary (CEM II) concrete redrawn after Hyvert [18]. 
First one can note the important scatter; this justifies the choice of the unique sample set. In addition, it can also be observed that the relative mass variation at the end of each $\mathrm{RH}$-step is not constant: the time elapsed on each step was not enough to achieve full equilibrium. Waiting for equilibrium would have been much too long and then impracticable. However, it is not believed to impact the validity of the results obtained, this point is discussed below.

\subsection{Desorption isotherm}

Since the samples were not at equilibrium at the end of each $\mathrm{RH}-$ step, the relative mass variation at equilibrium was estimated using an inverse analytical analysis of the results as already described by Tada and Watanabe [33] for a sphere. In our case the samples were assumed to be infinite solid cylinders (finite radius $R$ and infinite height) for which water transport is everywhere radial: the contribution of the sample ends was then neglected. The water transport was described using the diffusion Eq. (4) and the moisture diffusivity was assumed to be constant over the RH-step. The samples were assumed to be initially at equilibrium with the previous step $\mathrm{RH}$ (that is to say uniform initial water concentration). At $t=0$ another $\mathrm{RH}(h)$ was prescribed uniformly all over the cylinder external surface (uniform boundary condition). It was also assumed that it remained constant over time. The theoretical resulting relative mass loss is then analytically given by the following relation [11]:

$\left(\frac{m}{m}\right)(h, t)=\left(\frac{m}{m}\right)(h, \infty)\left[1-\sum_{n=1}^{\infty} \frac{4}{R^{2} \alpha_{n}^{2}} \exp \left(-D_{c} \alpha_{n}^{2} t\right)\right]$,

where the $\alpha_{n}$ s are the positive roots of the equation $J_{0}\left(R \alpha_{n}\right)=0$ ( $J_{0}$ is the Bessel function of the first kind of order zero); $R$ is the cylinder radius and $D_{c}$ is the (constant) moisture diffusivity for the considered RH-step. The relative mass loss $\left(\frac{m}{m}\right)(h, \infty)$ at equilibrium with the relative humidity $h$ was the one which gave the best fit of the experimental results using Eq. (8). For each sample the water content $w$ (by mass) or the saturation $S$ at equilibrium was computed using the following relations:

$$
w(h)=\frac{d_{s}}{d_{s}-\phi}\left[\frac{\phi}{d_{s}}+\left(\frac{\Delta m}{m}\right)(h, \infty)\right] \quad S(h)=\frac{w}{w_{\text {sat }}}=1+\frac{d_{s}}{\phi}\left(\frac{\Delta m}{m}\right)(h, \infty),
$$

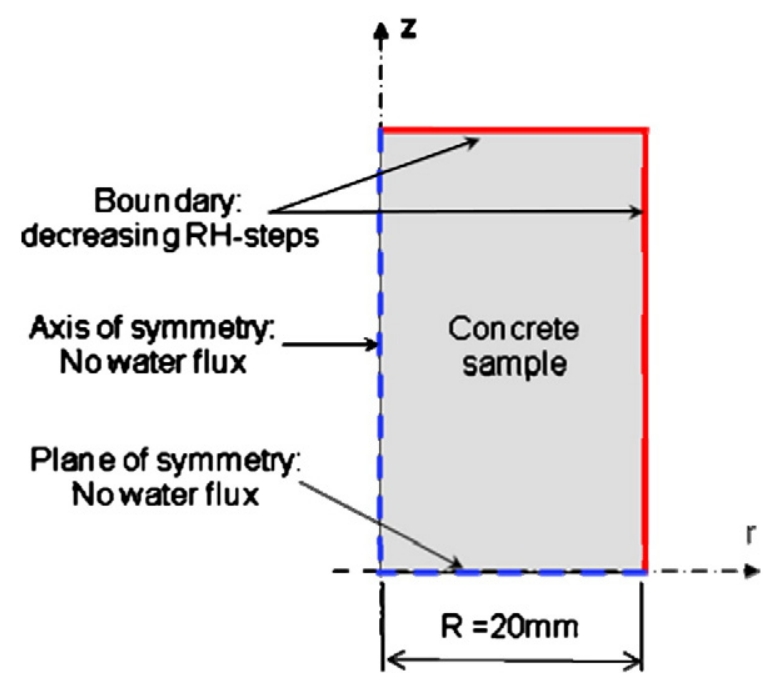

Fig. 4. Schematic description of the simulations carried out using the finite-element code Cast $3 \mathrm{~m}$ for water diffusivity assessment.

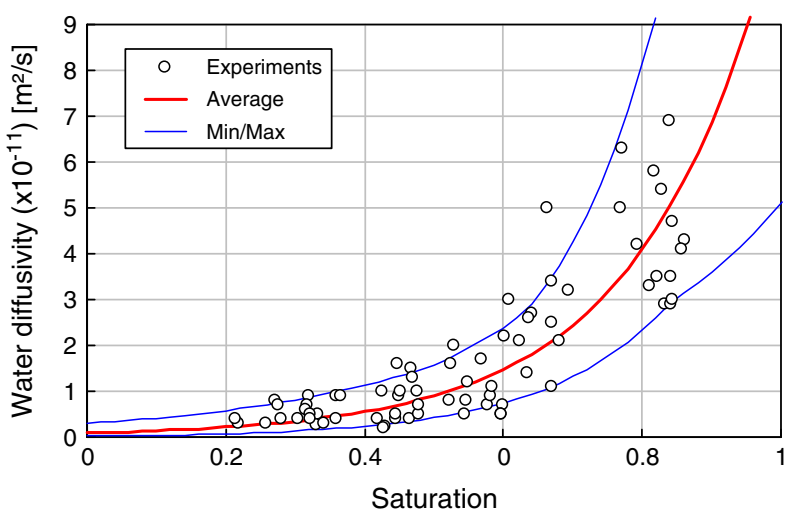

Fig. 5. Water diffusivity $D$ as a function of saturation for each sample.

where $d_{s}$ is the saturated sample specific gravity (ranging from 2.29 to 2.39 ) and $w_{s}$ is the water content at saturation (ranging from $5.57 \%$ to $7.90 \%$, see Table 2 ). The resulting desorption isotherm is depicted on Fig. 2 in terms of water content: one can see a very important scatter over the whole $\mathrm{RH}$ range as already observed in Fig. 1 (weight variation). Moreover the isotherm exhibits an unusual shape when compared to the reference results of Baroghel-Bouny et al. [5]: the quick fall in saturation for high $\mathrm{RH}$ is followed by an almost linear trend between $80 \%$ and $30 \%$ (with a low slope). The amount of water retained at low $\mathrm{RH}$ is high with respect to that at saturation.

For verification purpose, a remaining concrete sample part (a removed edge) was powdered and tested in a commercial sorption balance. ${ }^{2}$ This device was previously used by Johannesson et al. [19,21] and Anderberg and Wadsö [1] for cement-based materials and the comparison with other usual techniques $[20,2,13]$ was successful. The resulting isotherm is depicted in Fig. 2 (solid triangles): note that due to some differences in the experimental conditions (for the sorption balance the test temperature was $25^{\circ} \mathrm{C}$; the sample was powdered from a discarded part of more porous skin concrete and the powder was not dried at $105^{\circ} \mathrm{C}$ to estimate its porosity) a perfect correspondence cannot be expected and this result must be apprehended in a qualitative manner. Yet the isotherms obtained using the saturated salt solutions and the analytical solution (8) and the sorption balance are in good agreement: this is believed by the authors to give confidence in the method employed and the resulting isotherm.

In a recent study Hyvert [18] has characterized the impact of carbonation of the desorption isotherm of a mortar. The results obtained using a CEM II cement (clinker $+10 \%$ carbonate filler) are redrawn on Fig. 3 (the samples were carbonated at $20 \pm 2{ }^{\circ} \mathrm{C}$ and $\mathrm{RH}=65 \pm 5 \%$ at $50 \% \mathrm{CO}_{2}$ ). Hyvert found that carbonation has a great influence: the desorption isotherm of the carbonated samples is very different from the one obtained using the noncarbonated ones. Moreover it can be seen that the resulting isotherm of the carbonated samples is very similar to the one obtained in this study. It is then believed that the desorption isotherm is representative of a carbonated concrete. This is consistent with the fifty-year exposure to the atmosphere of the concrete structure.

\section{Diffusivity}

The evaluation of the transport properties was done in a classical way by comparing the experimental weight variations to the theoretical description of water transport within the samples. The

\footnotetext{
${ }^{2}$ Dynamic Vapor Sorption (DVS) from Surface Measurement Systems (SMS), Alperton, United Kingdom (http://www.thesorptionsolution.com).
} 
diffusion Eq. (4) was solved using the finite-element code Cast $3 \mathrm{~m}^{3}{ }^{3}$ The real geometry of each sample was described (that is to say the real height); the effect of both sample ends was then accounted. The simulations were carried out in axisymmetrical conditions (Fig. 4) using 8-node quadrangles (quadratic elements). The samples were initially saturated $(S=1)$; at $t=0$ they were submitted to the decreasing $\mathrm{RH}$-steps (Table 1 ). The temperature was kept equal to $20{ }^{\circ} \mathrm{C}$ during the calculations.

The diffusivity was determined to yield the best description of the experimental results. In practice, the diffusivity was assumed to be constant on each RH-step, and the best value was estimated by minimizing the quadratic difference between the measured and computed relative weight variations.

The diffusivity evolution versus saturation of each sample is presented on Fig. 5. As expected, the more the saturation the higher the diffusivity. Note that this evolution could be efficiently described using the classical exponential expression $[26,17,12,23]$ :

$D=D_{0} \exp \left(\alpha S_{l}\right)=D_{0} \exp \left(\alpha \frac{w}{w_{s}}\right)$

where $D_{0}$ is the dry concrete water diffusivity $\left(\mathrm{m}^{2} / \mathrm{s}\right)$ and $\alpha$ is a positive coefficient which generally lies between 3 and 7 [17]; for instance Denarié and Houst [12] found an average value of 4 for drying silica fume mortars whereas Leech et al. [23] obtained 6 for a concrete using Nuclear Magnetic Resonance and Boltzmann transformation of an imbibition test. In this study the values of $\alpha$ lie between 3.3 and 6.5 with an average value equal to 5.0 (Table 3 ). These results are in good accordance with previous observations $[26,17,12,23]$. The value of $D_{0}$ lies within $1.9 \mathrm{e}-13$ to $3.0 \mathrm{e}-12$ with an average value equal to $8.8 \mathrm{e}-13 \mathrm{~m}^{2} / \mathrm{s}$ : it is lower than the values obtained by Denarié and Houst [12] on silica fume mortars (by about one order of magnitude) but higher than the one proposed by Mensi et al. [26] to describe concrete drying $\left(D_{0}=1.04 \mathrm{e}-13 \mathrm{~m}^{2} / \mathrm{s}\right)$. These results are close to $D_{0}=1.4 \mathrm{e}-12 \mathrm{~m}^{2} / \mathrm{s}$ obtained by Benboudjema et al. [7] on the results of Granger [15] (Civaux B11). Once again the results present an important scatter: the coefficient of variation COV (it is defined as the ratio of the standard deviation to the mean value) of $D_{0}$ is equal to $86 \%$.

\section{Permeability}

Water permeability could be evaluated using the same approach as diffusivity (inverse analysis based on the mass variations); yet since this was already done for diffusivity it was preferred to deduce permeability directly from diffusivity. Starting from Eq. (4), introducing the pressure $P$ as the unknown and comparing to Eq. (3) one can easily show that there exists a simple relation between diffusivity and permeability [10]:

$K k_{r}=\eta \phi\left(\frac{\partial S}{\partial P}\right) D$

Knowing for each sample the diffusivity evolution and the desorption isotherm, the permeability evolution can then be easily assessed. Practically, the three-parameter law proposed by van Genuchten [37] (with the usual restriction $m=1-1 / n$ ) was used to describe the desorption isotherm:

$S=\left[1+\left(P / P_{0}\right)^{n}\right]^{-m}$

Table 4 recapitulates the values obtained for each sample.

\footnotetext{
${ }^{3}$ http://www-cast3m.cea.fr/.
}

Table 3

Parameters for the exponential water diffusivity.

\begin{tabular}{llr}
\hline Sample & Water diffusivity & \\
\cline { 2 - 3 } & $D_{0}\left[\mathrm{~m}^{2} / \mathrm{s}\right]$ & $\alpha[-]$ \\
\hline 1 & $2.0 \mathrm{e}-12$ & 4.127 \\
2 & $8.1 \mathrm{e}-13$ & 5.267 \\
3 & $7.0 \mathrm{e}-13$ & 4.789 \\
4 & $1.9 \mathrm{e}-13$ & 6.437 \\
5 & $1.5 \mathrm{e}-12$ & 3.497 \\
6 & $3.0 \mathrm{e}-12$ & 3.326 \\
7 & $5.4 \mathrm{e}-13$ & 5.913 \\
8 & $4.4 \mathrm{e}-13$ & 5.069 \\
9 & $2.4 \mathrm{e}-13$ & 5.704 \\
10 & $4.6 \mathrm{e}-13$ & 6.455 \\
11 & $4.4 \mathrm{e}-13$ & 4.999 \\
12 & $7.4 \mathrm{e}-13$ & 5.020 \\
13 & $5.2 \mathrm{e}-13$ & 5.121 \\
14 & $9.2 \mathrm{e}-13$ & 4.365 \\
15 & $6.4 \mathrm{e}-13$ & 5.516 \\
Average & $8.8 \mathrm{e}-13$ & 5.040 \\
Std dev. & $7.5 \mathrm{e}-13$ & 0.930 \\
COV & $86 \%$ & $18 \%$ \\
\hline
\end{tabular}

Differentiation of Eq. (9) leads to the derivative $(\partial S / \partial P)$ written in terms of pressure (top) or saturation (bottom):

$$
\begin{aligned}
\left(\frac{\partial S}{\partial P}\right) & =-\frac{m}{(m-1) P_{0}}\left(\frac{P}{P_{0}}\right)^{\frac{m}{1-m}}\left[1+\left(\frac{P}{P_{0}}\right)^{\frac{1}{1-m}}\right]^{-1-m} \\
& =-\frac{m}{(m-1) P_{0}} S^{1+1 / m}\left(S^{-1 / m}-1\right)^{m} .
\end{aligned}
$$

Thus introducing Eqs. (10) and (13) into Eq. (11) allows an easy and immediate assessment of the effective permeability $\left(K \times k_{r}\right)$ evolution versus saturation. Fig. 6 presents the results obtained (open circles) using Eq. (11). One can note the important decrease of the effective permeability with saturation (note the log-scale). Another important fact to be highlighted is the absence of smoothed experimental results close to saturation (typically for $S>0.90$ ). This is due to the fact that for $n$ greater than 1 the value of the derivative $(\partial S / \partial P)$ at saturation is equal to zero [38]: all the affected (and then irrelevant) points were then removed for clarity. In our case, using Eq. (11) together with van Genuchten law does not make it possible to derive a direct estimation of the intrinsic water permeability $K$ (i.e. the effective permeability for $S=1$ ).

Table 4

van Genuchten parameters for each sample $(m=1-1 / n)$.

\begin{tabular}{lrrr}
\hline Sample & \multicolumn{2}{c}{ van Genuchten parameters } & \multicolumn{1}{c}{} \\
\cline { 2 - 4 } & $P_{0}$ & $n$ & 0.203 \\
\hline 1 & 2.579 & 1.254 & 0.217 \\
2 & 4.038 & 1.278 & 0.198 \\
3 & 2.280 & 1.248 & 0.223 \\
4 & 3.718 & 1.286 & 0.186 \\
5 & 2.464 & 1.229 & 0.218 \\
6 & 2.131 & 1.279 & 0.240 \\
7 & 2.102 & 1.315 & 0.242 \\
8 & 6.331 & 1.319 & 0.246 \\
9 & 4.016 & 1.327 & 0.249 \\
10 & 2.565 & 1.331 & 0.248 \\
11 & 6.832 & 1.329 & 0.320 \\
12 & 12.763 & 1.470 & 0.307 \\
13 & 11.235 & 1.443 & 0.187 \\
14 & 2.658 & 1.230 & 0.176 \\
15 & 1.653 & 1.214 & 0.231 \\
Average & 4.491 & 1.303 & 0.041 \\
Std dev. & 3.411 & 0.073 & $18 \%$ \\
COV & $76 \%$ & $6 \%$ & \\
\hline
\end{tabular}




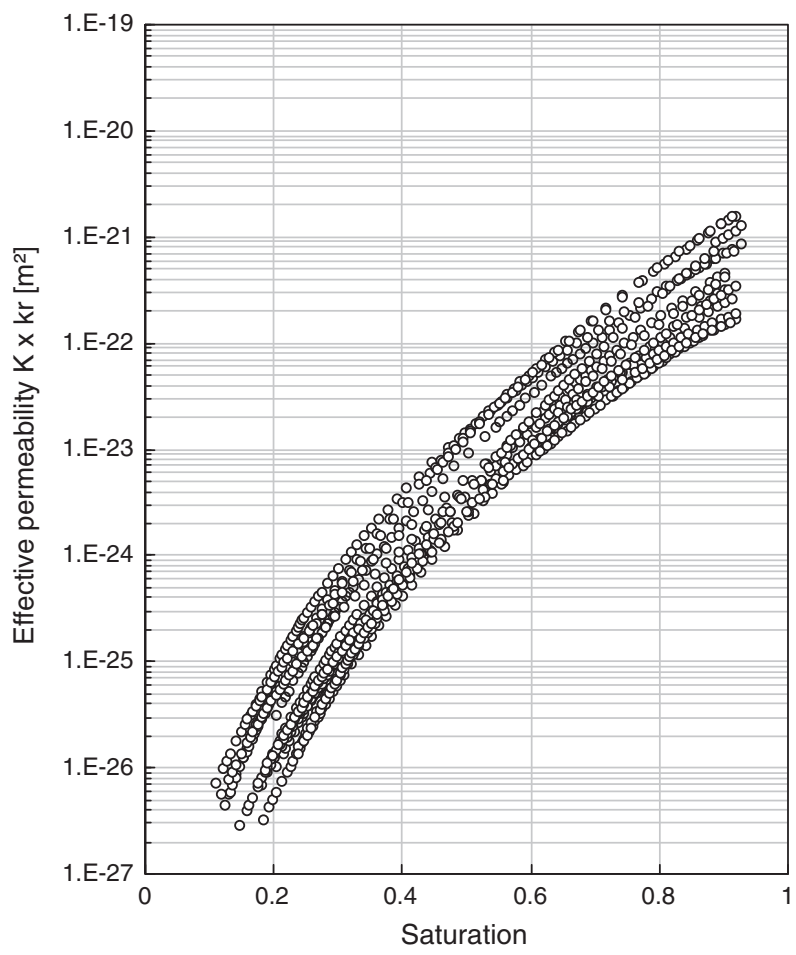

Fig. 6. Water permeability as a function of saturation derived from diffusivity using Eq. (8).

For this purpose, the equation derived by van Genuchten [37] on the basis of the model proposed by Mualem [28] was used to fit the effective permeability results $\left(K \times k_{r}\right)$ :

$K_{e}(S)=K k_{r}(S)=K S^{p}\left[1-\left(1-S^{\frac{1}{m}}\right)^{m}\right]^{2}$

This approach is commonly used for the evaluation of the hydraulic properties of soils [38]. Following Mualem [28] the default value $p=+0.5$ was used in a first approach. Note that for each sample, the $m$-parameter value was the one obtained for the isotherm fitting using Eq. (12) and the intrinsic permeability $K$ was chosen to give the best fit (to minimize the deviation between the model and the measurements).

One can see on Fig. 7 that the theoretical effective permeabilities deviate from the measurements: the deviation increases when saturation decreases to reach less than two orders of magnitude at $S=0.2$. Moreover when $S$ is greater than 0.5 the deviation is less than one order of magnitude. The corresponding intrinsic water permeabilities are reported in Table 5; the scatter is very important. ( $\mathrm{COV}=100 \%$ ). The estimation procedure does not appear to be fully satisfactory.

In a second approach, the pore-interaction factor $p$ was considered as an unknown value and was then identified together with the intrinsic permeability $K$. The fitted evolutions are depicted on Fig. 8: in this case (unlike the first approach, Fig. 7) the van Genuchten model (solid lines) and the experimental results (open circles) show an almost perfect match.

The resulting pore-interaction factor values $p$ are all negative (from -4.0 to -1.5 , see Table 5 ) with an average value equal to -2.6 . They are far different from the default value proposed by Mualem $(+0.5)$, the one obtained by Leech et al. [24] $(-0.5)$ and MonlouisBonnaire et al. [27] $(+5.5)$ : it is believed by the authors that this is an illustration of the variability already observed in soil science. Applying no restriction on the pore-interaction factor $p$ led to a better fit of the

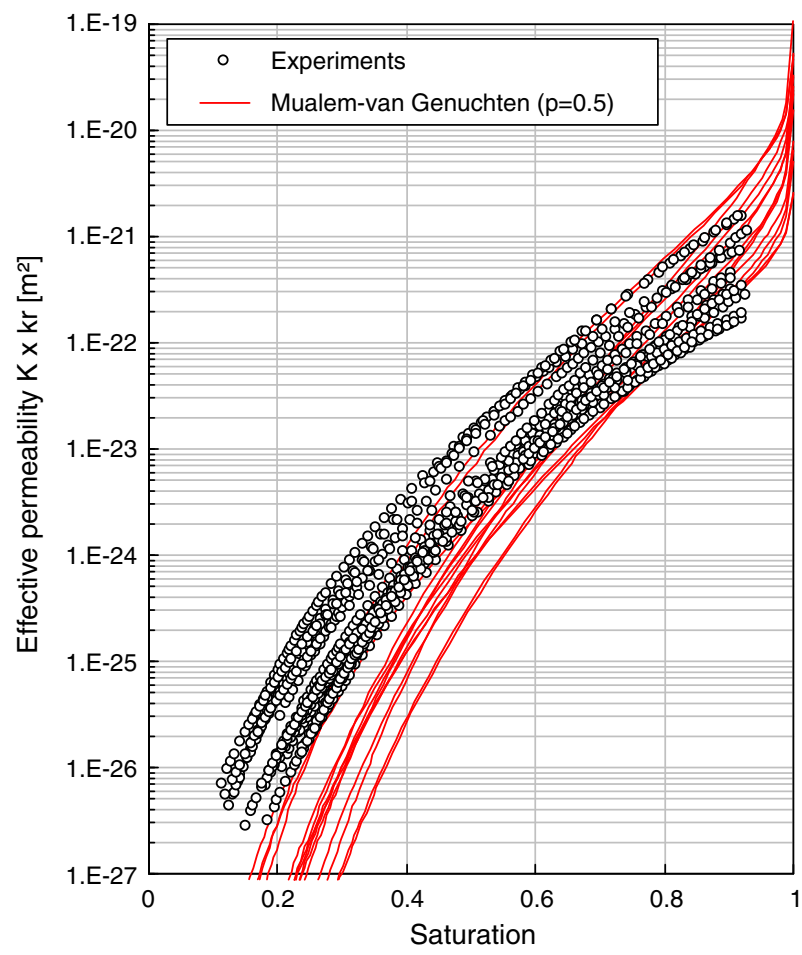

Fig. 7. Assessment of the effective water permeability using the closed-form equation proposed by van Genuchten [37] (using $p=0.5$ ). The deviation between the measurements and the model reaches two orders of magnitude for low saturations.

effective permeability (than the one obtained using $p=+0.5$ ). This also resulted in slightly less variability in the intrinsic permeability evaluation (Table 5): the COV is high (84\%) but is less than the one obtained (100\%) in the first approach (using $p=+0.5$ ). The values obtained spread between $1.3 \mathrm{e}-21$ and $34.8 \mathrm{e}-21 \mathrm{~m}^{2}$ with an average value equal to $10.9 \mathrm{e}-21 \mathrm{~m}^{2}$. Compared to literature the latter appears to be high: lying between the low-strength and the normal-strength concretes studied by Baroghel-Bouny et al. [5] (Table 6). Yet comparing the effective permeability evolutions (Fig. 9) acquired in

Table 5

Intrinsic permeability $K$ and pore-interaction factor $p$. The first approach consisted in using the default value $p=+0.5$ whereas the second considered it as an unnown value as well as the intrinsic permeability $K$.

\begin{tabular}{lllll}
\hline Sample & \multicolumn{3}{l}{ Intrinsic water permeability $\left(\mathrm{m}^{2}\right)$} \\
\cline { 2 - 4 } & \multicolumn{2}{l}{\begin{tabular}{l} 
First approach \\
\multicolumn{2}{l}{$(p=+0.5)$}
\end{tabular}} & \multicolumn{2}{l}{$\begin{array}{l}\text { Second approach } \\
\text { (variable } p)\end{array}$} \\
\cline { 2 - 5 } & $p$ & $K$ & $p$ & $K$ \\
\hline 1 & 0.5 & $52.4 \mathrm{e}-21$ & -3.3 & $19.8 \mathrm{e}-21$ \\
2 & 0.5 & $26.1 \mathrm{e}-21$ & -2.5 & $10.3 \mathrm{e}-21$ \\
3 & 0.5 & $31.4 \mathrm{e}-21$ & -3.1 & $11.7 \mathrm{e}-21$ \\
4 & 0.5 & $15.8 \mathrm{e}-21$ & -1.9 & $6.2 \mathrm{e}-21$ \\
5 & 0.5 & $22.4 \mathrm{e}-21$ & -4.0 & $9.4 \mathrm{e}-21$ \\
6 & 0.5 & $33.5 \mathrm{e}-21$ & -3.5 & $14.9 \mathrm{e}-21$ \\
7 & 0.5 & $49.9 \mathrm{e}-21$ & -2.1 & $18.3 \mathrm{e}-21$ \\
8 & 0.5 & $6.4 \mathrm{e}-21$ & -2.2 & $2.7 \mathrm{e}-21$ \\
9 & 0.5 & $7.7 \mathrm{e}-21$ & -2.0 & $3.4 \mathrm{e}-21$ \\
10 & 0.5 & $47.0 \mathrm{e}-21$ & -1.8 & $16.2 \mathrm{e}-21$ \\
11 & 0.5 & $5.1 \mathrm{e}-21$ & -2.2 & $2.4 \mathrm{e}-21$ \\
12 & 0.5 & $2.5 \mathrm{e}-21$ & -1.5 & $1.3 \mathrm{e}-21$ \\
13 & 0.5 & $2.6 \mathrm{e}-21$ & -1.6 & $1.3 \mathrm{e}-21$ \\
14 & 0.5 & $23.9 \mathrm{e}-21$ & -3.6 & $10.3 \mathrm{e}-21$ \\
15 & 0.5 & $115.7 \mathrm{e}-21$ & -3.3 & $34.8 \mathrm{e}-21$ \\
Average & 0.5 & $29.5 \mathrm{e}-21$ & -2.6 & $10.9 \mathrm{e}-21$ \\
Std dev. & - & $29.3 \mathrm{e}-21$ & +0.8 & $9.1 \mathrm{e}-21$ \\
COV & - & $100 \%$ & $32 \%$ & $84 \%$ \\
\hline & & & & \\
\hline
\end{tabular}


Table 6

van Genuchten parameters and intrinsic water permeability of three concretes studied by Baroghel-Bouny et al. [5].

\begin{tabular}{lccccc}
\hline Concrete & $\mathrm{w} / \mathrm{c}$ & $P_{0}(\mathrm{MPa})$ & $n$ & $m$ & $K\left(\times 1 \mathrm{e}-21 \mathrm{~m}^{2}\right)$ \\
\hline Low-strength concrete (LSC) & 0.84 & 13.1 & 1.78 & 0.437 & 45.00 \\
Normal-strength concrete (NSC) & 0.49 & 35.4 & 1.89 & 0.417 & 3.40 \\
High-strength concrete (HSC) & 0.27 & 106.6 & 2.78 & 0.640 & 0.16 \\
\hline
\end{tabular}

this study to the ones obtained by Thiery et al. [34] by inverse analysis of sample mass loss, one can see that there is a strong decrease for high saturation (one order of magnitude between 1 and 0.99). Except at saturation, the effective permeability presents values very similar to the normal-strength and the high-strength concretes. In fact the sharp decrease near saturation is due to the low value of $m$ (between 0.176 and 0.320 ) [38].

\section{Discussion: the pore-interaction factor}

From the results obtained above, it appears clearly that the poreinteraction factor $p$ is a material-dependent value which can greatly differ from the universal value usually used $(p=+0.5)$ to describe water transport within cementitious materials. One can wonder: can this difference have an influence on the water permeability evaluation? To answer this question the permeability to water was estimated independently on all the five different RH steps (Table 1 and Fig. 1) using the universal value of the pore-interaction factor ( $p=+0.5$ as proposed by Mualem [28] and used by Savage and Janssen [30]). In practice, the van Genuchten's equation (Eq. 11 together with $p=+0.5$ ) was used to fit the experimental effective permeability (Fig. 6) on each RH step. When the results were not available (that is to say at high $\mathrm{RH}$ ) the results of the second approach were used (in this second approach the pore-interaction factor was fitted in the same time as the van Genuchten's parameters this

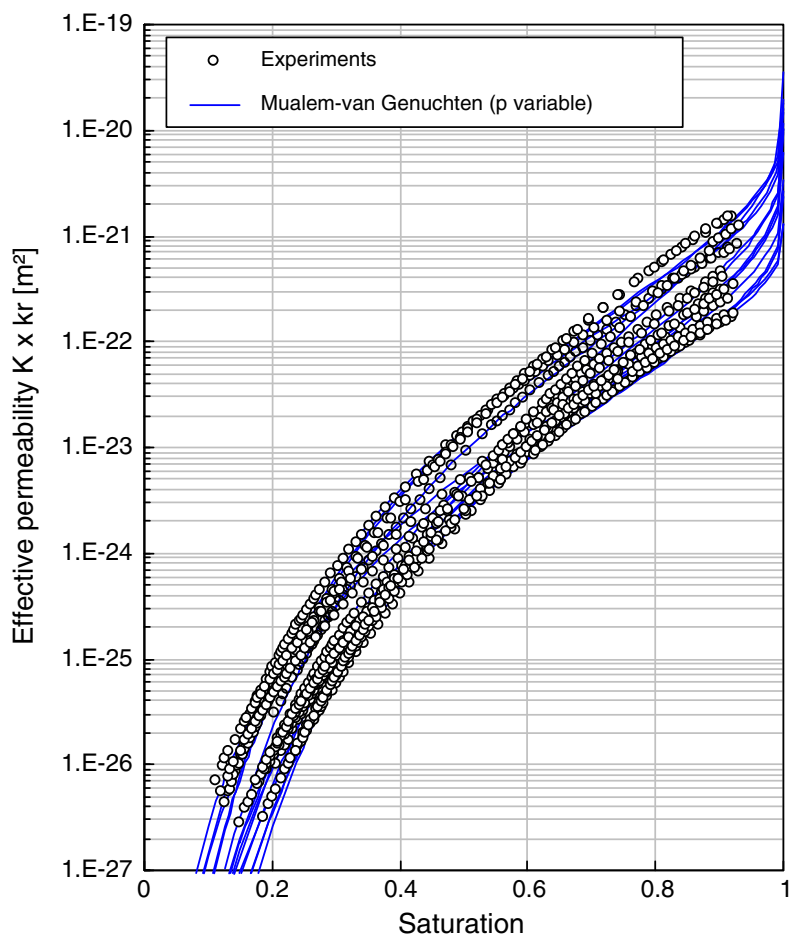

Fig. 8. Assessment of the effective water permeability using the closed-form equation proposed by van Genuchten [37]: the pore-interaction factor $p$ was also fitted for each sample. resulted in an almost perfect fit; Fig. 8). The values obtained were compared by computing for each sample the ratio $R_{K}$ :

$R_{K}=\frac{K_{i}}{K}$

where $K_{i}$ is the permeability obtained on the RH step $i$ whereas $K$ is the permeability best-estimate on all the RH steps (second approach of Table 5). Fig. 10 depicts the evolution of the ratio $R_{K}$ (for each RH step and for each sample) as a function of the absolute value of the difference between the fitted pore-interaction factor $p$ and the universal value $(+0.5)$.

It can be seen that whatever the RH step, the ratio $R_{K}$ increases when the difference $a b s(p-0.5)$ increases. This means that the error made in the permeability evaluation increases with the difference between $p$ and +0.5 . In addition the ratio $R_{K}$ is also found to vary with the $\mathrm{RH}$ step: the lower the $\mathrm{RH}$, the higher the ratio $R_{K}$. This is due to the fact that in the fitting process, the van Genuchten equation is forced to match only a certain portion of the curve and part of the deviation observed in Fig. 7 is directly transferred to the permeability value. Note that when the fitting is done near saturation (between $100 \%$ and $93 \%$ ) the ratio value is very low (less than 2 ) indicating that the estimated permeability is less than twice the real value. In this case the error is negligible. Yet when the fitting process is carried out for low RHs, the ratio can reach up to 100: in this case there are two orders of magnitude between the estimated permeability and the real value: the error is not negligible any more.

Analyzing the results, it appears that the pore-interaction was not correlated to the permeability $(K)$, total porosity $(\phi)$ or the van Genuchten's pressure $\left(P_{0}\right)$. Nevertheless comparing the pore-interaction factor $p$ to the van Genuchten's parameter $m$, a general trend could be observed: that is to say $p$ increases with $m$. This trend is illustrated in Fig. 11 in which are also reported the results obtained by Leech et al. [24] (using three different concretes) and the results obtained by Wösten and van Genuchten [40] (using 20 different soils). One can see that all the

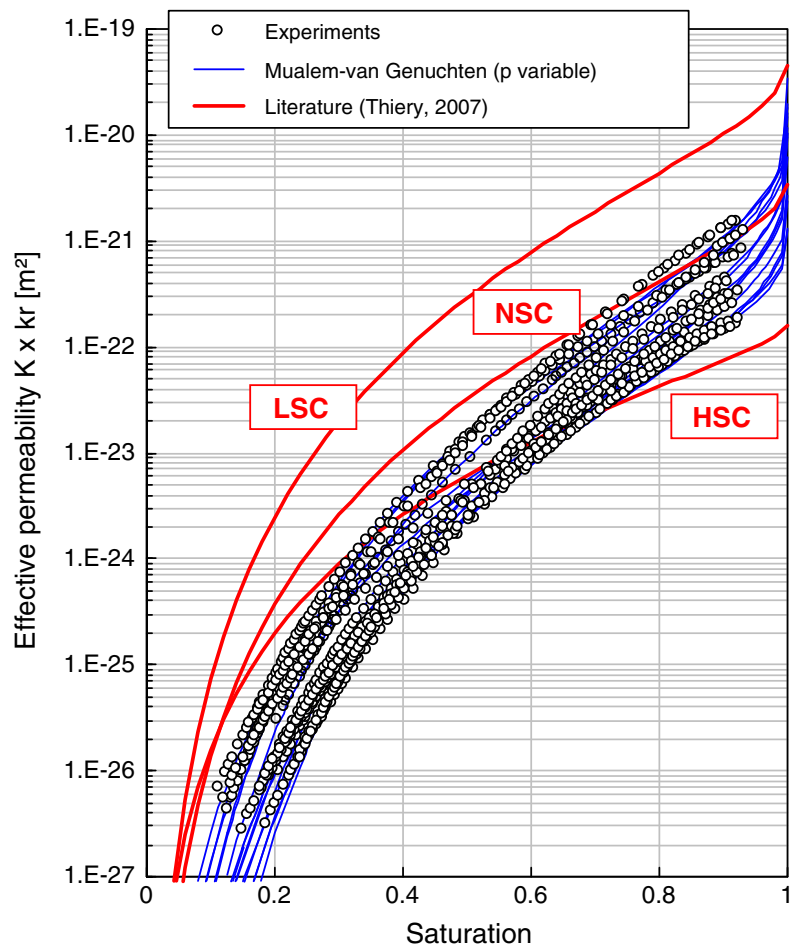

Fig. 9. Comparison of the effective permeability between the present study and literature. 


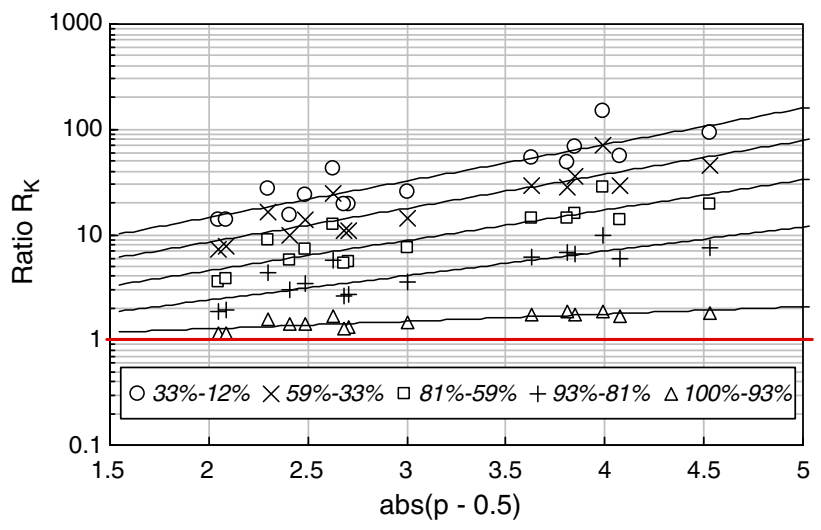

Fig. 10. Evolution of the ratio $R_{K}$ as a function of $a b s(p-0.5)$.

results seem to describe a similar trend in spite of the difference of materials considered (concretes and soils). The function used here to describe this trend is (the determination coefficient is $R^{2}=0.902$ ):

$p=4.991 \operatorname{Ln}(m)+4.744$.

It can be noted that for this logarithmic function the default value $p=0.5$ is obtained for $m=0.40-0.45$ which is the value commonly used for concretes (since it was found to correspond to an ordinary concrete [3-5,34]. Of course the existence of this trend must be apprehended with great caution: the amount of data on cementitious materials is clearly not enough and would be profitably complemented with other results. Moreover in soil science where large datasets are available, the absence of correlation between the pore-interaction factor and the van Genuchten's parameters was already reported (for instance by Schuh and Cline [31]).

\section{Conclusion}

The durability of concrete structures is greatly related to water transport; the first objective of this study was then to determine experimentally all the data needed for a good description of water transport within a concrete taken from an old real structure. The experiment consisted in drying concrete samples (at constant temperature but decreasing RHs) and measuring the weight loss evolution. The experiment was conducted in a dynamic way: the samples were not at equilibrium at the end of each $\mathrm{RH}$ step. This allowed the experiment not to exceed two years. The weight loss at equilibrium (desorption isotherm) as well as the water transport

\section{van Genuchten exponent $\mathrm{m}$}

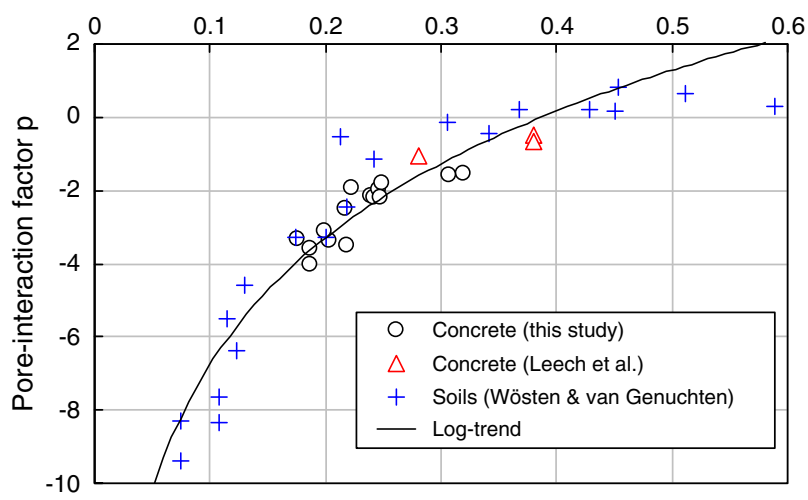

Fig. 11. Tentative of correlation between the van Genuchten's exponent $m$ and the pore-interaction factor $p$ : the open circles correspond to the results obtained in this study; the triangles correspond to three concretes from Leech et al. [24] and the plus marks correspond to 20 different soils from Wösten and van Genuchten [40]. properties (diffusivity and permeability) was estimated on the basis of the weight loss evolution versus time through inverse analysis. All the properties obtained show an important scatter.

Once obtained, the water transport properties were used to check the ability of the Mualem-van Genuchten equations to predict the evolution of the water relative permeability. In our study, using the universal pore-interaction factor $(p=+0.5)$ led to large differences between the real and the theoretical relative permeabilities. Considering the pore-interaction factor as a parameter to be fitted as well as the intrinsic permeability led to an almost perfect fit of the experimental permeability evolutions. The resulting pore-interaction factor values were all negative. The difference between the universal and the real pore-interaction factor values is believed to potentially induce errors in the permeability evaluation process (inverse analysis of sample weight loss) which can reach two orders of magnitude (depending on the fitting process). One has then to be very careful with the choice of an experimental procedure to fit the permeability.

Comparing the pore-interaction factor obtained in this study to other results (concretes and soils), a general trend seems to arise: the pore-interaction factor increases with the van Genuchten exponent $m$. This trend could be efficiently described using a logarithmic evolution. Additional studies would be necessary to validate this result.

\section{Acknowledgments}

The samples used in this study were cored and communicated by E. Marie-Victoire (Laboratoire de Recherche des Monuments Historiques - LRMH) within a PNRC project (French Ministry of Culture). The software PhiMeca Soft was used for the evaluation of the water transport properties; it allowed these operations to be fully automated. The first author would like to thank T. Yalamas (Phimeca) for his help. This study was financially supported by CEA through the CIMETAL research project.

\section{References}

[1] A. Anderberg, L. Wadsö, Method for simultaneous determination of sorption isotherms and diffusivity of cement-based materials, Cement and Concrete Research 38 (1) (2008) 89-94.

[2] P. Arlabosse, E. Rodier, J.H. Ferrasse, S. Chavez, D. Lecomte, Comparison between static and dynamic methods for sorption isotherm measurements, Drying Technology 21 (3) (2003) 479-497.

[3] V. Baroghel-Bouny, Water vapour sorption experiments on hardened cementitious materials: part I. Essential tool for analysis of hygral behaviour and its relation to pore structure, Cement and Concrete Research 37 (3) (2007) 414-437.

[4] V. Baroghel-Bouny, Water vapour sorption experiments on hardened cementitious materials. Part II. Essential tool for assessment of transport properties and for durability prediction, Cement and Concrete Research 37 (3) (2007) 438-454.

[5] V. Baroghel-Bouny, M. Mainguy, T. Lassabatère, O. Coussy, Characterization and identification of equilibrium and transfer moisture properties for ordinary and high-strength cementitious materials, Cement and Concrete Research 29 (8) (1999) 1225-1238.

[6] P.A.M. Basheer, Permeation analysis, in: Ramachandran, Beaudouin (Eds.), Handbook of Analytical Techniques in Concrete Science and Technology, Noyes Publication, Park Ridge, New Jersey, 2001, pp. 658-737.

[7] F. Benboudjema, F. Meftah, J.-M. Torrenti, Interaction between drying, shrinkage, creep and cracking phenomena in concrete, Engineering Structures 27 (2) (2005) 239-250.

[8] A. Carotenuto, M. Dell'Isola, An experimental verification of saturated salt solution-based humidity fixed points, International Journal of Thermophysics 17 (6) (1996) p1423-p1439.

[9] D.S. Carr, B.L. Harris, Solutions for maintaining constant relative humidity, Industrial and Engineering Chemistry 41 (9) (1949) 2014-2015.

[10] O. Coussy, V. Baroghel-Bouny, P. Dangla, M. Mainguy, Evaluation de la perméabilité à l'eau liquide des bétons à partir de leur perte de masse durant le séchage (in french), European Journal of Environmental and Civil Engineering 5 (2-3) (2001) 269-284.

[11] J. Crank, The Mathematics of Diffusion (Second Edition), Clarendon Press, Oxford, United Kingdom, 1975414 pp.

[12] E. Denarié, Y.F. Houst, Moisture diffusivity of fiber reinforced silica fume mortars, The Proceedings of 5th International Conference on Fly Ash, Silica Fume, Slag and Natural Pozzolans in Concrete. Milwaukee, American Concrete Institute, Wisconsin (USA), 1995, SP153-40. 
[13] Y. Fei, M. Marshall, W.R. Jackson, A.L. Chaffee, D.J. Allardice, A comparison of adsorption isotherms using different techniques for a range of raw, water- and acid-washed lignites, Fuel 85 (10-11) (2006) 1559-1565.

[14] H. Garbalińska, Application of $\sqrt{ } \mathrm{t}$-type, logarithmic and half-time methods in desorptive measurements of diffusivity in narrow range humidity ranges, Cement and Concrete Research 36 (7) (2006) 1294-1303.

[15] L. Granger, Comportement différé du béton dans les enceintes de confinement de centrales nucléaires: analyse et modélisation (in french). Ph.D. thesis, École Nationale des Ponts et Chaussées, Marne la Vallée, France, 1996, 398 pp.

[16] L. Greenspan, Humidity fixed points of binary saturated aqueous solutions Journal of Research of the National Bureau of Standards A: Physics and Chemistry $81 \mathrm{~A}(1)$ (1977) 89-96.

[17] C. Hall, Barrier performance of concrete: a review of fluid transport theory, Materials and Structures 27 (5) (1994) 291-306.

[18] N. Hyvert, Application de l'approche probabiliste à la durabilité des produits préfabriqués en béton (in french). Ph.D. thesis, University of Toulouse, France, 2009, 225 pp.

[19] B. Johannesson, Prestudy on diffusion and transient condensation of water vapor in cement mortar, Cement and Concrete Research 32 (6) (2002) 955-962.

[20] B. Johannesson, M. Janz, Test of four different experimental methods to determine sorption isotherms, Journal of Materials in Civil Engineering (ASCE) 14 (6) (2002) 471-477.

[21] B. Johannesson, P. Utgennant, Microstructural changes caused by carbonation of cement mortar, Cement and Concrete Research 31 (6) (2001) 925-931.

[22] K. Kosugi, General model for unsaturated hydraulic conductivity for soils with lognormal pore-size distribution, Soil Science Society of America Journal 63 (2) (1999) 270-277.

[23] C. Leech, D. Lockington, P. Dux, Unsaturated diffusivity functions for concrete derived from NMR images, Materials and Structures 36 (6) (2003) 413-418.

[24] C. Leech, D. Lockington, R.D. Hooton, G. Galloway, G. Cowin, P. Dux, Validation of Mualem's conductivity model and prediction of saturated permeability from sorptivity, ACI Materials Journal 105 (1) (2008) 44-51.

[25] M. Mainguy, O. Coussy, V. Baroghel-Bouny, Role of air pressure in drying of weakly permeable materials, Journal of Engineering Mechanics (ASCE) 127 (6) (2001) 582-592.

[26] R. Mensi, P. Acker, A. Attolou, Séchage du béton : analyse et modélisation (in french), Materials and Structures 21 (1) (1988) 3-12.
[27] J.P. Monlouis-Bonnaire, J. Verdier, B. Perrin, Prediction of the relative permeability to gas flow of cement-based materials, Cement and Concrete Research 34 (5) (2004) 737-744.

[28] Y. Mualem, A new model for predicting the hydraulic conductivity of unsaturated porous media, Water Resources Research 12 (3) (1976) 513-522.

[29] L.A. Richards, Capillary conduction of liquids through porous mediums, Physics 1 (5) (1931) 318-333.

[30] B.M. Savage, DJ. Janssen, Soil physics principles validated for use in predicting unsaturated moisture movement in Portland cement concrete, $\mathrm{ACl}$ Materials Journal 94 (1) (1997) 63-70.

[31] W.M. Schuh, R.L. Cline, Effect of soil properties on unsaturated hydraulic conductivity pore-interaction factors, Soil Science Society of America Journal 54 (6) (1990) 1509-1519.

[32] R.H. Stokes, R.A. Robinson, Standard solutions for humidity control at $25^{\circ} \mathrm{C}$, Industrial and Engineering Chemistry 41 (9) (1949) p2013.

[33] S. Tada, K. Watanabe, Dynamic determination of sorption isotherm of cement based materials, Cement and Concrete Research 35 (12) (2005) 2271-2277.

[34] M. Thiery, V. Baroghel-Bouny, N. Bourneton, G. Villain, C. Stéfani, Modélisation du séchage du béton, analyse des différents modes de transfert hydrique (in french), European Journal of Environmental and Civil Engineering 11 (5) (2007) 541-577.

[35] M. Thiery, P. Belin, V. Baroghel-Bouny, M. Nguyen, Modeling of isothermal drying process in cementitious materials: analysis of the moisture transfer and proposal of simplified approaches, in: Shao, Burlion (Eds.), Proceedings of the 3rd Symposium GeoProc, Lille, France, Wiley, 2008, pp. 571-579.

[36] K. Tuutti, Corrosion of steel in concrete, Report CBI 10/4/1982 (ISSN 0346-6906), Swedish Cement and Concrete Research Institute, 1982468 pp.

[37] M.T. Van Genuchten, A closed-form equation for predicting the hydraulic conductivity of unsaturated soils, Soil Science Society of America Journal 44 (5) (1980) 892-898.

[38] M.T. Van Genuchten, D.R. Nielsen, On describing and predicting the hydraulic properties of unsaturated soils, Annales Geophysicae 3 (5) (1985) 615-628.

[39] G. Wardeh, B. Perrin, Relative permeabilities of cement-based materials: influence of the tortuosity function, Journal of Building Physics 30 (1) (2006) 39-57.

[40] J.H.M. Wösten, M.T. van Genuchten, Using texture and other soil properties to predict the unsaturated soil hydraulic functions, Soil Science Society of America Journal 52 (1) (1988) 1762-1770.

[41] J.F. Young, Humidity control in the laboratory using salt solutions - a review, Journal of Applied Chemistry 17 (9) (1967) 241-245. 